\title{
Regional distribution and incidence of human papillomavirus infections among heterosexual men and women with multiple sexual partners: a prospective study
}

G J J Van Doornum, M Prins, L H J Juffermans, C Hooykaas, J A R van den Hoek, R A Coutinho, W G V Quint

detected only once in one of the participants. In women persistent HPV infection was more common than in men. Independent predictors for presence of HPV DNA in women were diagnosis of condylomata acuminata, reporting genital dermatologic abnormalties and age. Incidence of HPV infection in women turned out to be $47 \cdot 1$ infections per 100 person-years and for men 50.5 per 100 person-years.

(Genitourin Med 1994;70:240-246)

Introduction

Over the last decade knowledge about the epidemiology of human papillomavirus (HPV) infection has been expanding, but many controversial questions remain to be answered. Which anatomical sites are harbouring the latent or occult papillomavirus infections both in men and women?' What is the natural history of HPV infection and what is the subsequent risk of invasive cancer? ${ }^{2}$ To answer some of these questions we performed a longitudinal study among heterosexual men and women with multiple sexual partners to assess the prevalence, incidence and potential risk factors of genital HPV infections. In addition, we wanted to investigate the existence of latent and subclinical infection and to identify the niches of HPV.

Municipal Health Service of Amsterdam, Department of Public Health, Amsterdam, The Netherlands G J J van Doornum M Prins

C Hooykaas ${ }^{\star}$

$J$ A R van den Hoek

R A Coutinho

SSDZ, Diagnostic Centre, Delft, The Netherlands L H J Juffermans W G V Quint *Present affiliation: Ziekenfondsraad, Amstelveen, The Netherlands.

Address for correspondence: G J J van Doornum Municipal Health Service, Mepartment of Public Department of Puieu Health, Nieuwe Amsterdam, The Netherlands.

Accepted for publication 7 April 1994
Results-At entry of the study 37 (23\%) women and $24(28 \%)$ men were found positive for HPV DNA at any site. Only in one woman was oral presence of HPV DNA found during follow-up. Abnormal cervical cytology was observed in four women. In multivariate analysis, diagnosis of condylomata [odds ratio (OR) $5 \cdot 61$, $95 \%$ confidence interval (CI) 1.86 to 16.90)], reporting genital dermatological abnormalities (OR 3.72, 95\%CI 1.38 to 9.99) and age (OR per year $0.93,95 \%$ CI 0.88 to 0.99 ) predicted independently the presence of HPV DNA in women at entry of the study. In women 59 of the $99(60 \%)$ HPV infections were observed in the genital region and $40 \%$ in the anorectal region: in men these figures were $65 \%$ and $35 \%$, respectively. The incidence of HPV infection was $47 \cdot 1$ and 50.5 per 100 person-years for women and men respectively. At least $20 / 99(20 \%)$ infections in women were intermediate or long persistent and only $3 / 48(6 \%)$ HPV infections in men $(P=0 \cdot 03)$. No risk factor for persistency could be determined, either in women or in men.

Conclusions-HPV infection was found to be a multicentric genital and/or anorectal event both in women and men. The oral presence of HPV DNA was

\section{Material and methods \\ Study population}

From May 1988 to December 1990 participants were recruited among the visitors attending the STD Clinic of the Municipa Health Service of Amsterdam who had entered into a study on the heterosexua spread of HIV. Criteria for enrolment into the study were: age of 18 years or older and five or more heterosexual partners within 6 months before entry. As this study was originally designed to determine the heterosexual spread of the human immunodeficiency virus (HIV) haemophiliacs, men with homosexual contacts in the preceding 5 years and individuals having used drugs intravenously in the preceding 5 years were excluded. ${ }^{34}$ Written informed consent was provided by all participants. At each visit physical examination was performed and a standardised questionnaire was completed with questions on the medical 
history, HIV risk factors, sexual behaviour and social psychological variables. All participants underwent a standard STD examination at each visit. Of the 354 women and 267 men who entered the HIV study, 162 women and 85 men consented to be enrolled in the HPV study. Additionally, these participants underwent colposcopy, and were interviewed with a questionnaire concerning potential risk factors related to HPV infection.

Of the participants who entered the HPV study 110 women and 48 men could be followed until January 1992. In this group we determined the incidence and duration of HPV infection.

\section{Collection of specimens for HPV detection and cervical cytology}

Women. The specimens for HPV DNA detection were collected after a smear for cytological examination taken as described elsewhere. ${ }^{5}$ Specimens were obtained with wooden spatulas or cotton tipped applicators from the tongue and buccal mucosa, cervix, labia minora, anus and rectum. Standardised speculum examination and colposcopic evaluation of the vulva, cervix and vagina was performed before and after application of $3 \%$ acetic acid. In order to study the natural history of HPV infections no cervical biopsies were taken. Patients were referred to a gynaecological clinic, when cytologic and/or colposcopic evidence of cervical intraepithelial neoplasia developed.

Men. In men specimens for HPV DNA detection were collected with a sterile cotton tipped swab or wooden spatula from the tongue and buccal mucosa, the urethra, the coronal sulcus, anus and rectum. Clinical and colposcopic examination of the scrotal and penile regions was performed before and after the application of $3 \%$ acetic acid.

Because proctoscopy was experienced by most participants as being uncomfortable, we decided after the first sixty proctoscopies to collect blindly the rectal specimens making allowance for the fact that no mucosal abnormalities were detected.

Sample preparation and detection of HPV DNA The methods used for HPV DNA detection have been described elsewhere. ${ }^{6}$ In short, DNA extraction was carried out after pronase treatment and phenol/chloroform/isoamylalcohol extraction. The polymerase chain reaction (PCR) method was performed with four different primer sets as described by Claas previously. ${ }^{7}$ Four different reactions were performed, each with HPV 6/11, 16, 18 and 33 primers, separately. The amplified products were analysed by dot blot analysis. The filters were hybridised with a mixture of gamma- ${ }^{32} \mathrm{P}$ 5'-end-labelled HPV type specific oligonucleotide probes under conditions of high stringency.

Cervical cytology

The cervical smears were stained with Papanicolaou stain and classified according to standard criteria - the KOPAC system-as adopted in the Netherlands. ${ }^{89}$ Briefly, PAP I, normal cells; PAP II, inflammation; PAP III A, mild and moderate dysplasia; PAP III B, severe dysplasia; PAP IV, carcinoma in situ and PAP V, (micro-) invasive cancer.

\section{Definitions of clinical manifestation and type of} infection

The criteria of the different manifestations were defined as summarised by Syrjänen. ${ }^{10}$ Latent infection: HPV DNA positive; PAP smear, colposcopy and clinical inspection negative for any sign of HPV infection. Subclinical infection: HPV DNA positive and other signs of HPV infection only shown by magnification techniques such as colposcopy or cytology. Clinically manifest infection: HPV infection manifest both by presence of HPV DNA and by clinically overt lesions as condylomata acuminata.

For this study regional and temporal distribution of HPV infection was defined as follows. The sites of collecting the samples were divided in three regions: the genital, anorectal and oral region. Detection of a specific HPV DNA type in a region at one visit and no detectable HPV DNA within 365 days prior to and after the HPV DNA positive visit was regarded as a short, regressing infection. An infection with an intermediate level of persistency was defined as detection of HPV DNA of a specific type at two consecutive visits over a period of 365 days in one single region. Long persistency was defined as detection of the same type HPV DNA in one region at three or more consecutive visits over a period longer than 365 days without a negative visit in between. The participants only positive for HPV DNA at the first or last visit were regarded as having an infection of unknown duration as either persistency or regression was possible but could not be proven. Infections in persons attending the clinic irregularly during the follow-up period with intervals between successive visits longer than 365 days were regarded in a similar manner.

The following types of multiple infections were distinguished. Recurrent infection was defined as an infection with the same HPV type detected in one region at different visits while during the interval at least one HPV negative visit must have been recorded. Concurrent infections were defined as two or more infections with differing HPV types detected simultaneously in one anatomical region. Detection of the same HPV type in both the genital and anorectal region was considered to be a concomitant infection.

\section{Data analysis}

Categorical variables that were considered in the analysis were: demographic data such as residence, country of origin and education, history of genital warts, history of partners with genital warts, history of STDs in the previous 5 years and the past 4 months, having had private or commercial partners, use of hormonal contraception, current and past smoking, Pap smear diagnosis at entry, STDs (condylomata acuminata excluded) diagnosed at entry, having clinical manifest condylomata 
acuminata at entry and clinical manifest abnormalities in the anatomical regions studied.

Continuous variables analysed were: age, age at first sexual intercourse, menarche, years of hormonal contraceptive use, years of smoking, number of cigarettes per day, years involved in commercial sex and number of commercial and private sexual encounters in the period prior to entry.

For categorical variables associations with HPV infection were analysed using chi square tests or when appropriate Fisher's exact test. For continuous variables two tailed $t$ tests for independent samples were used and for data not normally distributed Mann-Whitney tests were used. Data univariately significantly related to HPV-status and potentially relevant but non-significant variables were used as independent variables in stepwise logistic regression analysis. All analyses were performed for men and women separately in order to construct a multivariate model predicting presence of HPV DNA. Significance was determined by the likelihood ratio statistic, a p-value $\leqslant 0.05$ was considered significant. All analyses were performed using the Statistical Package for Social Sciences (SPSS/PC +). ${ }^{11}$

\section{Results}

General characteristics of the total group at entry A description of the population that entered the study is presented in table 1 . The mean age of the 162 women was 30 years [standard deviation (SD)8] and 37 years (S.D. 10) of the 85 men. Both women and men reported a high number of commercial sexual contacts as reflected by the mean number of clients (41 per last month) or visits to prostitutes ( 4 per last four months). Forty-eight percent of the women reported STDs in the preceding 5 years and $40 \%$ of the men did so. Nine of the 19 women with condylomata acuminata had a clinically overt lesion, in 10 of them the lesions were seen only by colposcopy. In 10

Table 1 General characteristics of the total group of 162 women and 85 men with heterosexual multiple partners, at entry of the study

\begin{tabular}{|c|c|c|}
\hline & $\begin{array}{l}\text { Women } \\
N=162 \\
(\%)^{\star}\end{array}$ & $\begin{array}{l}M e n \\
N=85 \\
(\%)^{\star}\end{array}$ \\
\hline Age† & $30[8]$ & $37[10]$ \\
\hline Born in the Netherlands & $117(72)$ & $59(69)$ \\
\hline $\begin{array}{l}\text { Years of commercial sex } \dagger \\
\text { Number of clients/visits }\end{array}$ & $3[4]$ & 9 [11] \\
\hline last month $/ 4$ monthst & $41[77]$ & $4[7]$ \\
\hline $\begin{array}{l}\text { Number of private } \\
\text { partners last } 5 \text { years } \dagger\end{array}$ & $15[32]$ & $21[32]$ \\
\hline $\begin{array}{l}\text { Ever genital warts } \\
\text { Ever partners with }\end{array}$ & $49(31)$ & $21(26)$ \\
\hline genital warts & $35(23)$ & $8(14)$ \\
\hline $\begin{array}{l}\text { Reported STDs in } \\
\text { preceding } 5 \text { years }\end{array}$ & $77(48)$ & $34(40)$ \\
\hline Ever abnormal smear & $20(20)$ & 7 (11) \\
\hline Age of first intercourse & $16[2]$ & $17[3]$ \\
\hline Smoking current/past & $135(85)$ & $59(72)$ \\
\hline \multicolumn{3}{|l|}{ Diagnosis at entry } \\
\hline Pap IIIA & $4(3)$ & \\
\hline STDs $\ddagger$ & $14(9)$ & $4(4 \cdot 7)$ \\
\hline Condylomata acuminata & $19(12)$ & $11(13)$ \\
\hline
\end{tabular}

*Because of missing data some percentages are not based upon the total number of participants.

†Mean [standard deviation]

ISyphilis, gonorrhoea, Chlamydia trachomatis infection, genita herpes, and trichomoniasis (women only). men the condylomata were clinically overt and in one man only by colposcopy. A cervical smear at entry with cytologic result Pap IIIA was detected in four women. HIV antibody could be detected neither in women nor in men at entry as well as during follow-up.

\section{HPV DNA detection and clinical manifestation} at entry

The results of the HPV DNA detection at entry of the study are shown in table 2 . Thirty-seven $(23 \%)$ women and $24(28 \%)$ men were found with HPV DNA at any standard site of collection. HPV 18 was the most common type both in women and men; in $43 \%$ of HPV positive women and in $50 \%$ of the HPV positive men. HPV type 16 was detected in $41 \%$ and $33 \%$, respectively and HPV $6 / 11$ in $24 \%$ and $21 \%$, respectively. Two (5\%) women were diagnosed with HPV 33 at entry.

The clinical manifestation of the HPV DNA positive persons was analysed according to HPV DNA positivity at a standard site of collection. Seven of the 37 (19\%) HPV positive women showed evidence of clinical manifest infection, in $5(14 \%)$ subclinical HPV infection was detected, and in $25(68 \%)$ latent infection. In two of the $24(8 \%) \mathrm{HPV}$ positive men the infection was clinically visible, and in $22(92 \%)$ a latent infection was found. The presence of HPV DNA in condylomata acuminata was not assayed, because lesions are not biopsied at the Municipal STD Clinic. Therefore, in the above-mentioned figures only the laboratory proven HPV DNA-positive subjects were included. However, it is reasonable to consider all subjects with condylomata acuminata HPV 6/11 DNA positive. Then the total number of HPV DNA positive women would increase to 47 ; and the figures of the clinical manifestation of the infections were as follows for women. Nine of the $47(19 \%)$ women would have clinically manifest infections, 13 (28\%) subclinical (2 by cytology, one by cytology and colposcopy and 10 by colposcopy), and 25 (53\%) latent infections. Assuming a participant with an overt condyloma accminatum to be HPV 6/11 positive, the total number of HPV DNA positive men would become 31 and in 10 of them $(32 \%)$ the HPV infection was clinically overt, in one subclinical and in $20(65 \%)$ latent.

Risk factors for HPV DNA positivity at entry The analysis of possible risk factors was carried out for the total group at entry of the study, separately for women and men. The result of the analysis in women showed four variables univariately significantly differing between HPV positive and negative women. In multivariate analysis, except reporting more often STDs in the past 4 months, three variables remained significantly differentiating between HPV positive and HPV negative women: diagnosis of condylomata at entry of the study, self reported genital dermatological abnormalities such as genital herpes and candidiasis, and younger age predicted presence of HPV DNA independently. HPV DNA 
Table 2 Prevalence of HPV DNA in samples collected from 5 standard sites in 162 women and 85 men with multiple heterosexual partners at entry of the study, according to site of collection and HPV type

\begin{tabular}{|c|c|c|c|c|c|c|}
\hline \multirow[b]{2}{*}{ Site } & \multicolumn{3}{|l|}{$\begin{array}{l}\text { Women } \\
n=162\end{array}$} & \multicolumn{3}{|l|}{$\begin{array}{l}M e n \\
n=85\end{array}$} \\
\hline & $n(\%)^{\star}$ & HPV type & $(n)$ & $n(\%)^{\star}$ & HPV type & (n) \\
\hline Mouth & $0(0)$ & & & $0(0)$ & & \\
\hline Anus & $4(2 \cdot 5)$ & & $\begin{array}{l}(2) \\
(2)\end{array}$ & $1(1 \cdot 2)$ & 16 & (1) \\
\hline Rectum & $11(6 \cdot 8)$ & $\begin{array}{l}6 / 11 \\
16 \\
18 \\
33\end{array}$ & $\begin{array}{l}(3) \\
(3) \\
(4) \\
(1)\end{array}$ & $4(4 \cdot 7)$ & $\begin{array}{l}6 / 11 \\
16\end{array}$ & $\begin{array}{l}\text { (1) } \\
\text { (3) }\end{array}$ \\
\hline Urethra & & & & $16(18 \cdot 8)$ & $\begin{array}{l}6 / 11 \\
16 \\
18 \\
6 / 11+18\end{array}$ & $\begin{array}{l}\text { (3) } \\
(3) \\
(9) \\
(1)\end{array}$ \\
\hline Coronal sulcus & & & & $6(7 \cdot 1)$ & $\begin{array}{l}16 \\
18 \\
6 / 11+18\end{array}$ & $\begin{array}{l}\text { (2) } \\
\text { (3) } \\
\text { (1) }\end{array}$ \\
\hline Cervix & $25(15 \cdot 6)$ & $\begin{array}{l}6 / 11 \\
16 \\
16 \\
18 \\
6 / 11+16 \\
6 / 11+18\end{array}$ & $\begin{array}{l}(3) \\
(10) \\
(10) \\
(10) \\
(1) \\
(1)\end{array}$ & & & \\
\hline Labia minora & $11(6 \cdot 8)$ & $\begin{array}{l}6 / 11 \\
16 \\
18 \\
33 \\
6 / 11+16 \\
16+18\end{array}$ & $\begin{array}{l}(2) \\
(2) \\
(4) \\
(1) \\
(1) \\
(1)\end{array}$ & & & \\
\hline $\begin{array}{l}\text { HPV DNA + ve } \\
\text { at } \geqslant 1 \text { site }\end{array}$ & $37(22 \cdot 8)$ & & & $24(28 \cdot 2)$ & & \\
\hline
\end{tabular}

${ }^{\star}$ Because of missing data some percentages are not based upon the total number of participants.

positivity was predicted by presence of condylomata acuminata rather strongly [adjusted odds ratio (OR) $5 \cdot 61,95 \% \mathrm{CI} 1 \cdot 86$ to $16 \cdot 90$ ]. Adjusted OR of history of self reported genital dermatological abnormalities was 3.72 (95\%CI 1.38 to 9.99$)$ and the adjusted OR of age per year was $0.93(95 \% \mathrm{CI} 0.88$ to 0.99$)$. In men no significant risk factors were identified.

No association was found between HPV type and possible risk factors such as country of origin of the participant.

\section{Characteristics of the follow-up group}

One hundred and ten women were followed over a period of 155.1 person-years (411 visits). For women the mean duration of the follow-up period was 513 days $(S D=256)$ and the mean interval between the visits 188 days $(S D=96)$. Forty-eight men were followed over a period of 65.4 person-years with a total number of 172 visits. The mean duration of follow-up was 498 days $(S D=269)$ with a mean interval between visits of 193 days $(S D=110)$ between the visits. With respect to potential HPV risk factors as smoking, use of oral contraceptives and age of sexual debut the follow-up group did not differ significantly from those not followed.

Regional distribution of HPV infection, multiple infections over the follow-up period and recurrent infections

At entry of the study 23/110 (21\%) women and $15 / 48(31 \%)$ men of the follow-up group were diagnosed with HPV DNA at any site. The regional distribution of HPV infection in the follow-up group at entry of the study did differ only slightly from that found in the total group. The pattern observed during the follow-up period will be considered below more in detail.
Women. In $58(52 \%)$ of the 110 women a total of 99 infections was observed, $23(21 \%)$ women were HPV positive at entry and another $35(32 \%)$ turned out to be HPV positive during the follow-up period. Fifty-nine/99 $(60 \%)$ infections were detected in the genital region; 14 of the $59(24 \%)$ were both at the cervix and the labia minora and the remaining 45 were seen either at the cervix or the labia minora. Thirty-nine/99 (39\%) infections were found in the anorectal region, 14 of the 39 $(36 \%)$ both at the anus and rectum and 25 either at the anus or rectum. Concomitant infection of the same HPV type both in the genital and anorectal region was seen in 10/99 cases. Concurrent infection defined as two or more infections with differing HPV types detected simultaneously in the same anatomical region was observed in six women. Six recurrent infections were found in women, three in the genital region and three in the anorectal region. The mean interval between the two positive visits (in between at least one negative visit) was 520 days $(S D=215)$. Only one female participant was found positive for HPV DNA 16 in the oral cavity at one visit. Another specimen collected from the labia minora 246 days after the oral HPV positive visit was positive for HPV 33 .

Men. In 29 of the $48(60 \%)$ men 49 infections were diagnosed. Fifteen of 48 (31\%) men were HPV positive at entry and another $14(29 \%)$ during the follow-up period. Of the 49 infections $32(65 \%)$ were detected in the genital region. Eight of the $32(25 \%)$ infections were found both in the urethra and the coronal sulcus and 24 infections were seen in either the urethra or coronal sulcus. Seventeen $(35 \%)$ infections were found in the anorectal region, 4 of the $17(24 \%)$ both at the anus and the rectum and 13 at either the anus or rectum. Concomitant infections of the same HPV type in both regions were seen in two cases. In men two genital and two anorectal concurrent infections were observed. Recurrent infection was detected in the genital region of one man.

\section{Incidence of HPV infection at any site}

At entry of the study $26 \mathrm{HPV}$ infections were diagnosed in 23/110 women of the follow-up group. Seventy-three new infections were observed over the follow-up period of $155 \cdot 14$ person-years. The incidence in women was $47 \cdot 1(95 \% \mathrm{CI} 33 \cdot 8$ to $60 \cdot 3)$ new HPV infections per 100 person-years.

In the male follow-up group $16 \mathrm{HPV}$ infections were observed at entry in 15/48 men. Over a period of 65.41 person-years 33 newly acquired infections were detected resulting in $50.5(95 \%$ CI 29.7 to 71.2$)$ new infections per 100 person-years.

\section{Duration of infection}

The results of the genital and anorectal infections are presented in table 3. Of the 99 (98 + one oral infection) infections in 58 women 5 were persistent for more than one year and 15 were intermediate persistent resulting in a minimal persistency rate of $20 \%$. Thirty-one 
Table 3 Regional distribution of HPV infection among 110 women and 48 men of the follow-up group, by HPV type and duration of infection

\begin{tabular}{|c|c|c|c|c|c|}
\hline \multirow[b]{2}{*}{ Type } & \multirow[b]{2}{*}{ Infection } & \multicolumn{2}{|c|}{ Genital* region } & \multicolumn{2}{|c|}{ Anorectalt region } \\
\hline & & $\begin{array}{l}\text { Women } \\
n(\%)\end{array}$ & $\begin{array}{l}\text { Men } \\
n(\%)\end{array}$ & $\begin{array}{l}\text { Women } \\
n(\%)\end{array}$ & $\begin{array}{l}\text { Men } \\
n(\%)\end{array}$ \\
\hline \multirow[t]{4}{*}{$6 / 11$} & Persistent & 3 & - & 1 & 1 \\
\hline & Short & 5 & 3 & 3 & 2 \\
\hline & Unknown & 6 & 3 & 5 & 1 \\
\hline & Subtotal & 14 & 6 & 9 & 4 \\
\hline \multirow[t]{4}{*}{16} & Persistent & 5 & - & 2 & 1 \\
\hline & Short & 7 & 2 & 4 & 5 \\
\hline & Unknown & 8 & 4 & 7 & 3 \\
\hline & Subtotal & 20 & 6 & 13 & 9 \\
\hline \multirow[t]{4}{*}{18} & Persistent & 5 & 1 & 2 & - \\
\hline & Short & 2 & 7 & 3 & 2 \\
\hline & Unknown & 8 & 10 & 10 & 1 \\
\hline & Subtotal & 15 & 18 & 15 & 3 \\
\hline \multirow[t]{4}{*}{33} & Persistent & 2 & - & - & - \\
\hline & Short & 5 & 2 & 2 & 1 \\
\hline & Unknown & 3 & - & - & - \\
\hline & Subtotal & & & 2 & 1 \\
\hline \multirow[t]{3}{*}{ Total } & Persistent & $15 \quad(25)$ & $1 \quad(3)$ & $5(14)$ & $2(12)$ \\
\hline & Short regr. & 19 (32) & 14 (43) & $12(31)$ & $10(59)$ \\
\hline & $\begin{array}{l}\text { Unknown } \\
\text { Total }\end{array}$ & $\begin{array}{l}25(42) \\
59(100)\end{array}$ & $\begin{array}{l}17(53) \\
32(100)\end{array}$ & $\begin{array}{l}22(56) \\
39(100)\end{array}$ & $\begin{array}{r}5(29) \\
17(100)\end{array}$ \\
\hline
\end{tabular}

*Standard sites: cervix, labia minora (women); urethra, coronal sulcus (men).

†Standard sites: anus, rectum (women and men).

(31\%) infections were short lasting with proven regression and the duration of 48 $(48 \%)$ infections was unknown. Broken down to HPV type, the frequency of persistency for HPV $6 / 11$ positive women was $4 / 23(17 \%)$ for HPV $167 / 33$ (21\%), for HPV $187 / 30$ (23\%) and for HPV $332 / 12$ (17\%). An overal persistency of $5 / 39(13 \%)$ was found in the anorectal region and persistency in the female genital region was $15 / 59(25 \%)$

In men 3 of the $49(6 \%)$ infections of intermediate persistency were observed, $24(49 \%)$ short infections with known regression and 22 (45\%) infections with unknown duration. Of the 32 genital infections one $(3 \%)$ was intermediate persistent, $14(44 \%)$ were short lasting and of $17(53 \%)$ the duration was unknown. In the anorectal region $2 / 17(12 \%)$ of the infections were intermediate persistent, $10 / 17(59 \%)$ were short lasting and of unknown duration were 5/17 (29\%).

The subgroup of women with an intermediate or long persistent infection was compared with the HPV positive subgroup without known persistent infection regarding base-line characteristics. No difference for any of the variables above mentioned in the data analysis section was observed. In men the number of persistent infections was too small to analyse in detail. Persistency of HPV infection was statistically significantly observed more often in women (unadjusted OR 3.88 , $95 \%$ CI 1.06 to 21.34 ) compared to men.

\section{Cervical cytology during follow-up}

In four women of the follow-up group the result of cervical cytology was Pap IIIA at one or more visits. According to consensus in the Netherlands, cases with Pap IIIA are followed cytologically every three months. ${ }^{8}$ One woman with Pap IIIA was positive for HPV $6 / 11$, two women for type 16 , and in one women HPV 33 was detected. After referral to a gynaecologic clinic biopsy was performed in two of the four women. In the biopsy of one woman signs of a flat condyloma were seen, and in the biopsy of the other woman signs of viral infection were reported. In the woman with a flat condyloma in the biopsy a subsequent PAP smear remained Pap IIIA, and three others showed Pap II over a period of 739 days.

\section{Discussion}

In this prospective cohort study among heterosexual women and men with multiple partners the incidence of HPV infection and the regional distribution of HPV infection were studied. A relatively high rate of HPV 18 was observed. It has been reported that in cervical carcinoma from Indonesian women HPV 18 is dominantly present. ${ }^{12}$ Country of origin was, however, not a risk factor for HPV type in the present study.

\section{Regional distribution of HPV infection}

With regard to genital HPV infection, comparison with results from other studies is hampered by use of different techniques to detect HPV DNA and by different age groups. ${ }^{1314215}$ The same holds true for both female cervical and male urethral HPV infection. ${ }^{16}{ }^{17}$ The prevalence of HPV DNA in both anal and rectal swabs from women observed in our study group was lower than that in the biopsy samples reported by Scholefield in a control group. ${ }^{18}$ Our results of anorectal HPV infection in men are in part in accordance with the few reports on anal HPV infections in heterosexuals with genital warts. ${ }^{192021}$ In a control group consisting of surgical out-patient attenders without history or signs of anal warts, HPV DNA was detected from anal brushings in $3 \%(2 / 71) .^{21}$

With regard to the oral presence of HPV DNA our results are in contrast to the findings of others. ${ }^{22} 2324$ Jenison et al reported detection of HPV $6 \mathrm{~b}$ and HPV 16 DNA in $17 \%$ and $23 \%$ of oral mucosal samples, respectively. ${ }^{23}$ In the study reported by Kellokoski et al oral biospy samples from normal buccal mucosa of women with genital HPV infection were tested, and 23\% (18/78) of the samples contained HPV 6/11, 16 or 18 DNA detected by PCR. ${ }^{24}$ The estimated number of viral copies was low compared with genital mucosa. High prevalence figures of oral presence of HPV 16 have also been recently reported by Jalal et al. ${ }^{22}$ In $13 / 30$ $(43 \%)$ of the individuals scrapings from buccal mucosa, hard palate and dorsum of the tongue HPV 16 DNA could be detected. In a second group the samples collected from the 3 sites were pooled, $44 \%$ (8/18) were HPV 16 positive. In these experiments the sensitivity level was fewer than 5 HPV 16 genomes per sample. In the present study sensitivity of HPV 16 was determined to be $10 \mathrm{pg} \mathrm{SiHa}$ DNA in 100 ng placenta DNA, that is, 1-10 HPV 16 genomes per sample. ${ }^{15}$ Variability in sampling cannot be the only cause of such a difference in oral prevalence of genital HPV types. However, the results of the present study support the findings of Kashima et al who examined tissue specimens from clinically normal oral tissue at a corresponding 
contralateral site of a lesion using Southern transfer hybridisation. ${ }^{25}$ Only six of 119 samples (5\%) were HPV $(6 / 11,16,18$ and 31) DNA positive and by reverse blot hybridisation another 3 (HPV 3, 13, and 57 related). The reliability of the results of the present study is strengthened by the repeated sampling during the follow-up period. We conclude that presence of genital HPV types in oral scrapes is a rare event.

\section{Simultaneous presence of HPV infection}

Concerning the simultaneous presence of HPV infection, evidence of multicentric infection was found both in women and men. Within the female genital region a quarter of the infections were detected as being simultaneously present at the cervix and labia minora. Also in men a quarter of the genital infections were simultaneously present in the urethra and the coronal sulcus. Thirty six percent of the anorectal infections in women and $24 \%$ of the male anorectal infections were found to be simultaneously present at both sites of collection in this region. These results corroborate our previous findings reported on a smaller number of the group studied. ${ }^{5}$ Our new results support also the results of other studies. The anatomical distribution of HPV infection in cervical, urethral or vulvar lesions has been studied by Reid $e t a l^{6}$ and Rymark et $a l .{ }^{27}$ Both studies reported a high frequency of simultaneous occurrence of HPV DNA in cervical and vulvar or urethral sample. In the study of Reid et al at least $53 \%$ of specimens collected from biopsies from adjacent or normal epithelium secondary to areas with principal lesions were HPV DNA positive. Rymark et al reported that $61 \%$ of a small group of women with current or previous condylomata were positive for identical HPV DNA both in the cervix and urethra.

The frequency of concurrent infections, that is, infections with differing HPV types in the same region, was $5 \%$ and $8 \%$ in women and men, respectively. In women 10/98 $(10 \%)$ and in men $2 / 49(4 \%)$ of the infections were concomitant, that is, the same HPV type could be detected both in the genital and anorectal region.

Based on the observations of the present study, we conclude that infection of genital HPV types both in females and males is a multicentric event in the genital region as well as in the anorectal region.

Incidence and duration of HPV infection The high incidence of HPV infection in women and men may reflect that the proportion of HPV DNA positive individuals grows with increasing number of examinations over time and of collecting specimens at multiple anatomic sites. To the best of our knowledge figures to compare with have not appeared in the literature. In the approach followed to calculate the incidence, the number of personyears of follow-up was assumed to be equivalent to person-years at risk. In fact, a participant diagnosed with HPV infection has to be censored for the time of the infection with that specific type of HPV. However, at the same time the participant will be at risk of acquiring an infection with another HPV type.

The relatively high number of infections with an unknown duration of infection is partly due to the definitions used in this study. This category included all infections detected at entry of the study which were not classified as persistent infection and all infections detected for the first time at the last visit of the follow-up. Furthermore, infections detected in persons with too long intervals between consecutive visits were included in this category.

Several prospective studies on the clinical course of HPV infection in women have been published. ${ }^{28} 29$ The issue of duration of HPV infection as defined in our study is not addressed in these studies. The data presented in these studies do not provide sufficient information relating to the duration of HPV DNA positivity. The duration of HPV infection differed between HPV DNA positive women and men as persistency appeared to be significantly more often observed in women. To the best of our knowledge this difference has not been reported previously. The size of the cohort precluded a more detailed analysis of the duration of infection by regional distribution and HPV type.

Although it should be of interest, we did not analyse the relationship between the duration of infection and clinical manifestation for several reasons. The theoretical number of different patterns of the course of the clinical manifestation increases exponentially at each visit resulting into too small groups for comparison. Therefore, it was decided to consider only the HPV DNA positivity in the analysis of the duration of the HPV infection.

\section{Cervical cytology and HPV DNA results}

Regarding the cytological findings the results of the present prospective study do not support the data of the study reported by Koutsky et $a .^{2}$ In that study a surprisingly large proportion of high grade cervical intraepithelial neoplasia after the first HPV DNA positive cervical smear was detected. The percentage of women with Pap IIIA in our study is not appreciably greater than the frequency of 3\% of mild and severe dysplasia in cervical scrapes collected during general screening of the Amsterdam population..$^{30}$ Maybe the high proportion of HPV 18 in our study is in part an explanation for the differences observed. The problem of labelling the same cytologic conditions with different names may only be solved by exchange of specimen for comparison.

\section{Conclusion}

In this selected group of women and men with multiple partners HPV infection was found to be a multicentric genital or anorectal event (or both) both in women and men. In only one of the participants was the oral presence of HPV DNA detected. In women persistent HPV infection was found significantly more frequently than in men. The incidence of HPV 
infection was found to be high, $47 \cdot 1$ infections per 100 person-years for women and 50.5 for men.

We thank Sylvia van der Lans who performed the colposcopic examinations. We are examinations. We are grateful to Professor O P Bleker for
reviewing the slides of the colposcopic pictures and to Dr J ter reviewing the slides of the colposcopic pictures and to Dr J ter
Schegget for reading critically the manuscript. The authors Schegget for reading critically the manuscript. The authors
thank G Pel, J Kint, W van Bolderik, $R$ Wielings, A Thiele, thank G Pel, J Kint, W van Bolderik, $R$ Wielings, A Thiele,
and the personnel of the Clinic for Sexually Transmitted and the personnel of the Clinic for Sexually Transmitted
Diseases of the Municipal Health Service, Amsterdam for their Diseases of the Municipal Health Service, Amsterdam for their
help in conducting this study. P van Delft is acknowledged for help in conducting this study. P van Delft is acknowledged for
his technical assistance to complete the PCR tests. Part of this study was supported by the Dutch Foundation for Preventive Medicine, (grant 28-1529)..$^{12}$

1 Crum CP, Nuovo GJ. Genital Papillomaviruses and Related Neoplasms. Raven Press, New York 1991;88-105.

2 Koutsky L, Holmes KK, Critchlow CW, et al. A cohor study of the risk of cervical intraepithelial neoplasia grade 2 or 3 in relation to papillomavirus infection N Engl f Med 1992;327:1272-8.

3 Hooykaas C, Van der Pligt J, Van Doornum GJ, Van der Linden MMD, Coutinho RA. Heterosexuals at risk for HIV: Differences between private and commercial partners in sexual behaviour and condom use. AIDS 1989; 3:525-32.

4 Van der Linden MMD, Van der Velde FW, Hooykaas C, Van Doornum GJ, Coutinho RA. HIV-prevalentie onder heterosexuelen met veel wisselende partners in onder heterosexuelen met veel wisselende partners

5 Van Doornum GJ, Hooykaas C, Juffermans LHJ, et al. Prevalence of human papillomavirus infections among Prevalence of human papillomavirus infections among
heterosexual men and women with multiple partners. heterosexual men and wom

6 Melchers W, Van den Brule A, Walboomers J, et al. Increased detection rate of human papillomavirus in cervical scrapes by the polymerase chain reaction as compared to modified FISH and Southern-blot analysis. 7 Med Virol 1989;27:329-35.

7 Claas ECJ, Melchers WJG, Van der Linden HC, Lindeman J, Quint WGV. Human papillomavirus detection in paraffin embedded cervical carcinomas and metastases of the carcinomas by the polymerase chain reaction. Am ₹ Pathol 1989;135:703-9.

8 Vooys GP. De advisering bij afwijkende bevindingen van cytologisch onderzoek van de cervix uteri. Ned Tijdschr cytologisch onderzoek van

9 De Vet HCW. Cytologische diagnostiek van baarmoederhalskanker; classificatiesystemen ter discussie. Ned Tijdschr Geneeskd 1990;134:1435-7.

10 Syrjänen KJ. Natural history of genital human papillomavirus infections. In: Lacey C, ed "Papillomavirus Report. International Literature on Papillomavirus Infection. Oncology Information Service and Royal Society of Medicine Services Limited." Leeds: Leeds University Press 1990;1:5:1-5.

11 Norusis WJ. SPSS/PC + 4·0. Chicago:SPSS, Inc. 1990.

12 Bosch FX, Munoz N, Sherman M, et al. The prevalence of HPV in cervical cancer: a worldwide perspective. Twelfth International Papilloma Conference 1993, Baltimore.

13 Kiviat NB, Koutsky LA, Critchlow CW, et al. Prevalence and cytologic manifestations of human papilloma virus
(HPV) types $6,11,16,18,31,33,35,42,43,44,45$ 51,52 and 56 among 500 consecutive women. Int $\mathscr{f}$ Gynecol Pathol 1992;11:197-203.
14 Lorincz AT, Reid R, Bennett Jenson A, Greenberg $M$, Lancaster W, Kurman RJ. Human papillomavirus infection of the cervix: relative risk associations of $15 \mathrm{com}$ mon anogenital types. Obstet Gynecol 1992;79:328-37.

15 Van den Brule AJC, Claas ECJ, Du Maine M, et al. Use of anticontamination primers in the polymerase chain reaction for the detection of human papilloma virus genotypes in cervical scrapes and biopsies. $\mathcal{F}$ of Med Virol 1989;29:20-7.

16 Kataoka A, Claesson U, Hansson BG, Eriksson M, Lindh E. Human papillomavirus infection of the male diagnosed by Southern-blot hybridization and polymerase chain reaction: Comparison between urethra samples and penile biopsy samples. F Med Virol 1991;33:159-64.

17 Hippeläinen MI, Syrjänen S, Hippeläinen MJ, Saarikosk $S$, Syriänen $K$. Diagnosis of genital human papillomavirus (HPV) lesions in the male: Correlation of penismavirus (HPV) lesions in the male: Correlation of peniscopy, histology and

18 Scholefield JH, Hickson WGE, Smith JHF, Rogers K, Sharp F. Anal intraepithelial neoplasia: part of a multifocal disease process. Lancet 1992;340:1271-3.

19 Scholefield JH, Talbot IC, Whatrup C, Sonnex C, Palme JG, Mindel A. Anal and cervical intraepithelial neoplasia: possible parallel. Lancet 1989;ii:765-9.

20 Sonnex C, Scholefield JH, Kocjan G, et al. Anal human papillomavirus infection in heterosexuals with genital warts: prevalence and relation with sexual behaviour. BMF 1991;3033:1243.

21 Sonnex C, Scholefield JH, Kocjan G, et al. Anal human papillomavirus infection: a comparative study on cytology, colposcopy and DNA hybridisation methods of ogy, colposcopy and DNA hybridisation

22 Jalal H, Sanders CM, Prime StS, Scully C, Maitland NJ. Detection of human papilloma virus type 16 DNA in oral squames from normal young adults. $\mathcal{F}$ Oral Patho oral squames from nom

23 Jenison SA, Yu XP, Valentine JM, Koutsky LA, et al. Evidence of prevalent genital-type human papillomavirus infections in adults and children. 7 Infect $D i$ 1990;162:60-9.

24 Kellokoski JK, Syriänen SM, Chang F, Yliskoski M Syrjänen KI. Southern blot hybridization and PCR in detection of oral human papillomavirus (HPV) infections in women with genital HPV infections. $f$ Oral Pathol Med 1992;21:459-64.

25 Kashima HK, Kutcher M, Kessis T, Shah K, et al. Human papillomavirus in squamous cell carcinoma, leukoplakia, lichen planus, and clinically normal epithelium of the oral cavity. Ann Otol, Rhinol Laryngol 1990;99:55-61.

26 Reid R, Greenberg M, Bennett Jenson A, et al. Sexually Reid R, Greenberg M, Bennett Jenson A, et al. Sexually
transmitted papillomaviral infections. I. The anatomic distribution and pathologic grade of neoplastic lesion associated with different viral types. Am F Obstet Gynecol 1987;156:212-22.

27 Rymark P, Forslund O, Hansson BG, Lindholm K Genital HPV infection not a local but a regional infection: experience from a teenage group. Genitourin Med 1993;69:18-22.

28 Campion MJ, McCance DJ, Cuzick J, Singer A Progressive potential of mild cervical atypia: prospective cytological, colposcopic, and virological study. Lancet 1986;ii: $237-40$.

29 Lorincz AT, Schiffman MH, Jaffurs WJ, Marlow J, Quinn AP, Temple G. Temporal associations of human papilAP, Temple $\mathrm{G}$. Temporal associations of human papillomavirus infection with cervical cytol

30 Schrader PC. Bevolkingsonderzoek op baarmoederhalskanker, Amsterdam, 1990. Report Municipal Health Service of Amsterdam 1991:9. 